\title{
Sustentabilidade econômica das instituições de longa permanência para idosos
}

Economic sustainability of long-stay institutions for the elderly

Fátima de Souza Freire', Luiz Henrique de Mendonça', Abimael de Jesus Barros Costa ${ }^{3}$

1 Doutora em Economia pela Université des Sciences Sociales de Toulouse I -

Toulouse, França. Professora Associada do Departamento de Ciências Contábeis e Atuárias da Universidade de Brasília (UnB) Brasília (DF), Brasil.

freire@unb.br

2 Bacharel em Ciências Contábeis pela

Universidade de Brasília (UnB) - Brasília (DF),

Brasil.

luizhm87@gmail.com

${ }^{3}$ Mestre em Ciências Contábeis pela Universidade de Brasília (UnB) - Brasília (DF), Brasil. Professor Assistente do Departamento de Ciências Contábeis e Atuárias da UnB -

Braślia (DF), Brasil.

acosta@unb.br
RESUMO O objetivo do trabalho é verificar a forma de sustentabilidade econômica e o valor do custo de permanência de um idoso nas Instituições de Longa Permanência para Idosos - ILPIs. Foram coletadas informações das despesas e receitas de quatro instituições, por meio da aplicação de um questionário e de entrevista, em maio de 2011. O resultado da pesquisa mostra que há uma insuficiência de recursos destinados às instituições, sendo que a principal fonte de arrecadação das filantrópicas são as doações da comunidade, com o suporte da prestação de serviços voluntários. Os recursos do governo representam uma parcela pouco expressiva, pois para cada idoso com razoável condição física o governo repassa $\mathrm{R} \$ 6,71$, enquanto para os incapacitantes o valor chega a $\mathrm{R} \$ 7,81$.

PALAVRAS CHAVE: Envelhecimento; Idoso; Qualidade de vida.

ABSTRACT The purpose of this study is to verify the form of economic sustainability and the cost of staying of an elderly in Long Stay Institutions for Aged People. Information about income and expenditure of four institutions were collected through a questionnaire and interview in May 2011. The research result shows that there is a failure of resources destined for the institutions where the main source of revenue comes from philanthropic donations from the community, with the support of volunteer service. The government resources represent a nonsignificant portion because for every elderly person in reasonable physical condition the government passes $R \$ 6.71$, while for the disabled the value reaches $R \$ 7.81$.

KEYWORDS: Aging; Elderly; Quality of Life. 


\section{Introdução}

O envelhecimento populacional é um fenômeno observado mundialmente, que requer mudanças comportamentais e culturais, visto que ocorrerá um crescimento mais elevado da população idosa em relação aos demais grupos etários.

Com o aumento da população idosa, há também um aumento de doenças crônicas e incapacitantes, bem como uma mudança na saúde pública (RAMOS, 2003). A depressão, por exemplo, é um problema de saúde mental comum nos mais velhos e está associada à diminuição da qualidade de vida, dificultando o funcionamento diário das pessoas, bem como aumentando o risco de suicídio (BOJORQUEZ-CHAPELA et al, 2009). Envelhecer, nesse contexto, constitui-se grande desafio para os indivíduos, a sociedade e o governo, no sentido de oferecer condiçóes adequadas para o prolongamento da vida (RODRIGUES; RAUTH, 2002).

Sandiford e Divers (2011) investigaram o papel social das casas de apoio aos necessitados, especificando os aspectos históricos e os contextos atuais com relação aos mais diversos grupos marginalizados dentro da comunidade britânica. $\mathrm{O}$ trabalho deixa debates quanto a questóes relacionadas à marginalidade, ao possível fechamento, à manutenção e ao papel social que as casas desempenham para uma camada da sociedade com sérios problemas de alcoolismo ou outros tipos de doenças.

Uma vez que o número de idosos em Brasília passará de 197 mil, em 2010, para 484 mil, em 2030, o que representa um acréscimo de 245\% (IBGE, 2011), o segmento merecerá uma atenção especial de pesquisadores, gestores e políticos, exigindo um exame mais aprofundado das situaçóes econômica e social das entidades ligadas à oferta de serviços especializados para pessoas idosas. A principal fonte de suporte para a população de idosos ainda é a família, principalmente aquela que coabita com ela. Muitas vezes, os familiares são os membros mais pobres da família, tendo sérios problemas de saúde, o que causa desconforto ao idoso. O tamanho da família está em diminuição, enquanto o número de pessoas com idade avançada está aumentando. Além disso, a mulher - principal responsável pelos cuidados aos idosos - busca novos trabalhos fora do seu domicílio (RAMOS, 2003). Ferreira, Alexandre e Lemos (2011) reforçam o papel da mulher na sociedade ao tratarem dos benefícios gerados aos idosos com a assistência domiciliar. Em estudo realizado com 40 cuidadores de idosos de um Programa de Assistência Domiciliária da cidade de São Paulo, concluiu-se que foi encontrado idoso cuidando de outro idoso mais dependente, situação que influencia aspectos físicos, emocionais e sociais que contribuem diretamente para seu isolamento social. Conforme Laranjeira (2010, p. 763), “[...] a velhice é uma fase da vida que tem sido socialmente desvalorizada e negativamente representada, o que se reflete na qualidade de vida dos idosos".

Um número razoável de idosos não tem condições financeiras desejáveis, e muitos são encaminhados às casas de repouso ou asilos subsidiados pelo governo ou por entidades filantrópicas. Só em 2003, havia no Distrito Federal nove instituiçóes filantrópicas e duas casas de repouso particulares atendendo mais de 700 idosos (MELO et al, 2003). Vale frisar que Cader et al (2006) analisaram o perfil da autonomia funcional e a qualidade de vida do idoso em uma instituição filantrópica do Rio de Janeiro, apresentando o sedentarismo como um fator marcante e contribuinte para que o idoso se torne dependente mais cedo, causando depressão e doenças crônicas. Denota-se, ainda, que estudos voltados para a manutenção e a melhoria de condiçóes de vida em instituiçóes de longa permanência se tornam de grande importância, tendo em vista a relevância social que as mesmas proporcionam à sociedade. Logo, analisar a sustentabilidade de entidades que cuidam dos idosos é um tema de bastante relevância social, que necessita de uma significativa atenção do governo, da comunidade e da mídia.

Nesse cenário, busca-se entender qual é a forma de sustentabilidade econômica das instituiçôes de longa permanência para idosos no Brasil. Para a realização do estudo, buscou-se analisar as condiçóes de sustentabilidade de instituições filantrópicas e não filantrópicas localizadas no Distrito Federal. O estudo limita-se a investigar a gestão das instituiçóes públicas e privadas destinadas a idosos, e não contém informaçóes individuais a respeito do idoso. Considerando que o estudo 
não aborda seres humanos, não é necessário aval do comitê de ética para a pesquisa em tela.

Além da introdução, o trabalho está dividido em mais quatro seções. $\mathrm{Na}$ seção 2, discute-se o conceito de sustentabilidade econômica das entidades sem fins lucrativos, bem como a necessidade de políticas públicas para as ILPIs. A seção 3 apresenta a metodologia utilizada para a coleta de dados e a definiçáo de informações necessárias para a obtenção de valores de gastos, custos e despesas das instituições. $\mathrm{Na}$ seção 4, é apresentado o resultado da pesquisa com as seis instituições localizadas no DF. Por fim, na seção 5, são apresentadas as consideraçóes mediante os resultados obtidos.

\section{Sustentabilidade e políticas públicas}

A palavra sustentabilidade vem do latim sustinere, que significa manter vivo ou defender; já o conceito está relacionado com a continuidade das entidades nos mais diversos aspectos econômicos, sociais e ambientais. A sustentabilidade é considerada, atualmente, como sinônimo de desenvolvimento, incluindo as seguintes dimensóes: econômica, social, cultural, físicoterritorial e ambiental, político-institucional, científico-tecnológica e também espiritual (LOURES, 2009).

O termo também se relaciona com emergência, com desenvolver o capital humano e social capaz de construir habilidades de autorregulação em sistemas complexos. Sustentabilidade é a capacidade de sustentar ou suportar algo exigido nas mais diversas condiçóes. Pode ser entendida como parte de um processo de permanência.

Muitas entidades de caráter filantrópico ainda possuem a visão de que elas precisam de recurso do Estado e da comunidade para se manterem vivas, mas esse conceito tem mudado ultimamente (YUNUS, 2008). As organizaçóes de sociedade civil dependem de doaçôes do governo e de agências de cooperação internacional, mas têm diversificado a sua base de sustentabilidade. É possível ver que algumas entidades já incluem princípios de negócios em suas estratégias, obtendo fontes mistas de recursos provenientes tanto de atividades próprias, como a venda de produtos e serviços, como de diferentes parceiros (MCKINSEY, 2006).

Dois conceitos ainda precisam ser esclarecidos: 'sustentável' e 'sustentado'. Pode-se entender que uma entidade é sustentável quando ela está apta ou passível de sustentação, enquanto uma entidade sustentada é aquela que já tem garantida sua sustentação.

Uma das formas de se alcançar a sustentabilidade é fazê-la por meio de recursos do governo. E, para tanto, faz-se necessário criar políticas públicas. Não existe uma única (nem a melhor) definição para o que seja política pública. Mead (1995 apud HOCHMAN; ARRETCHE; MARQUE, 2008) define política pública como um campo dentro do estudo da política que analisa o governo à luz de grandes questôes públicas. Para Lynn (1980 apud HOCHMAN; ARRETCHE; MARQUE, 2008), significa um conjunto de açóes do governo que irá produzir efeitos específicos.

A política pública de atenção ao idoso, consagrada na Constituiçáo Federal de 1988, se relaciona com o desenvolvimento socioeconômico e cultural, bem como com a ação reivindicatória dos movimentos sociais.

Segundo Caramaro e Pasinato (2004, p.253), apesar de o envelhecimento populacional ser amplamente reconhecido como uma das principais conquistas sociais do século XX, reconhece-se também que traz grandes desafios para as políticas públicas.

Em janeiro de 1994, foi criada a Política Nacional do Idoso, com normas para garantir os direitos sociais do idoso, criando condiçóes para promover sua autonomia, integração e participação efetiva na sociedade de pessoas maiores de sessenta anos de idade, conforme artigos $1^{\circ}$ e $2^{\circ}$ da Lei no 8.842 , de 4 de janeiro de 1994 .

A Política Nacional do Idoso objetiva criar condiçóes para promover a longevidade com qualidade de vida, colocando em prática açóes voltadas não apenas para os que estão velhos, mas também para aqueles que vão envelhecer, além de listar as competências das várias áreas e de seus respectivos órgãos. A implantação dessa lei estimulou a articulação dos ministérios setoriais para o lançamento, em 1997, de um Plano de Ação Governamental para Integração da Política Nacional do Idoso. Os órgãos que compóem esse plano são os 
Ministérios da Previdência e Assistência Social, da Educação, da Justiça, da Cultura, do Trabalho e Emprego, da Saúde, do Esporte, do Turismo, dos Transportes e do Planejamento, Orçamento e Gestão.

Em outubro de 2003, foi instituído o Estatuto do Idoso, destinado a regular os direitos das pessoas com idade igual ou superior a 60 anos (artigo $\left.1^{\circ}\right)$. O mesmo determina que os idosos gozem de todos os direitos inerentes à pessoa humana, além de garantir proteção, facilidade e privilégios condizentes com a idade (artigo $2^{\circ}$ ).

Não há consenso, no Brasil, sobre o que seja uma Instituição de Longa Permanência para Idosos (ILPI). Sua origem está ligada aos asilos, que constituem a modalidade mais antiga de atendimento ao idoso fora do convívio familiar. Estes eram inicialmente dirigidos à população carente, que necessitava de abrigo. Por isso, muitas instituiçôes brasileiras se autodenominam abrigos (CARAMAGO, 2008).

A internação do idoso em uma instituição de longa permanência é uma alternativa em certas situações, quando se verificam a necessidade de reabilitação, a ausência temporária do cuidador domiciliar, os estágios terminais de patologias e a dependência elevada (CHAIMOWICZ, 1999).

Hoje, as ILPIs devem estar adaptadas e regulamentadas perante as leis para manter um padrão mínimo de funcionamento. A Agência Nacional de Vigilância Sanitária (ANVISA) estabelece normas a serem aplicadas em todas as ILPIs, governamentais ou não, sem fins lucrativos ou privadas, destinadas à moradia coletiva para pessoas de 60 anos de idade ou mais, com ou sem suporte familiar, que atendam pessoas idosas com variaçôes de dependência, ou seja, aquelas que requerem o auxílio de outras ou de equipamentos especiais para a realização das atividades da vida diária (ANVISA, 2005).

Sem dúvida, é inquestionável a importância de que o idoso viva no âmbito familiar e na comunidade. Entretanto, nem todos os idosos nem todas as famílias reúnem as condiçóes para manter o idoso em casa. Quando não há essa possibilidade, entram em cena as Instituiçóes de Longa Permanência para Idosos, tradicionalmente conhecidas como asilos, casas de repouso, clínicas de repouso, lares dos velhinhos e outras tantas nomenclaturas.
Por definição, segundo o manual de funcionamento da Sociedade Brasileira de Geriatria e Gerontologia (SBGG), Seção São Paulo, Biênio 2002/2003, atualmente, as ILPIs são estabelecidas para atendimento integral institucionalizado em cuidados prestados a pessoas de 60 anos de idade ou mais, dependentes ou independentes, que não dispóem de condições para permanecer com familiares ou em seu domicílio. Devido ao grau de importância das ILPIs para a sociedade, a seguir será apresentado o estudo realizado nas entidades localizadas no Distrito Federal.

\section{Método}

Trata-se de um estudo descritivo e exploratório, visto que tem como principal objetivo proporcionar informaçóes mais detalhadas sobre o assunto investigado, e que pretende orientar a formulação de novos objetivos acerca do funcionamento das ILPIs no Distrito Federal. Cabe ressaltar que, além das ILPIs, existem ainda outras instituiçóes de atendimento ao idoso, tais como centros de convivência e associações.

Justifica-se o estudo nessa regiáo porque a participação da população acima de 60 anos de idade passou de 4,01\% do total de habitantes, em 1990, para 5,35\%, em 2000 (IBGE, 2000). Projeçóes do IBGE e da Companhia de Planejamento do Distrito Federal (COMPANHIA DE PLANEJAMENTO DO DISTRITO FEDERAL, 2009) mostraram que a participação passará de $7,69 \%$, em 2010 , para quase $15 \%$ do total da população em 2030. Dados do Conselho dos Direitos do Idoso do Distrito Federal (CONSELHO DOS DIREITOS DO IDOSO DO DISTRITO FEDERAL, 2009) relatam que, dos 177 mil idosos existentes no DF, 24\% recebem até um salário mínimo; 19,4\%, entre 1 a 2 salários; 46,4\%, acima de 2 salários; e 10,2\% estão incluídos em outras classes de rendimento mensal. Vale frisar que $47,5 \%$ dos idosos do DF são aposentados e muitos contribuem com mais de $50 \%$ a $90 \%$ no rendimento mensal domiciliar.

Assim, busca-se verificar, na prática, e de forma estruturada, a situação financeira das casas onde os 
idosos são abrigados, conhecendo-se melhor as fontes de recursos e os seus principais gastos.

As instituições pesquisadas foram escolhidas com base em um levantamento feito pelo Conselho dos direitos do idoso do Distrito Federal (2009), apresentando dez ILPIs localizadas no Distrito Federal. Em seguida, os gestores das instituiçóes foram contatados, mas apenas seis se propuseram a participar da pesquisa.

Um questionário foi elaborado em quatro partes. A saber: (i) entidade: os principais dados, elencando as atividades desenvolvidas, o tempo de existência, o número de funcionários e o número de voluntários; (ii) perfil dos idosos: quantidade e gênero dos idosos; (iii) fontes de recursos: tipo de fontes de recursos; (iv) gastos: demonstração das principais despesas da instituição. Uma limitação ocorreu no levantamento dos gastos com fraldas geriátricas, alimentos, produtos de limpeza ou itens de qualquer outra natureza que não tenham sido adquiridos com dinheiro, pois dificultou a mensuração acurada das despesas da instituição, podendo, ainda, não estar contemplados na consolidação dos dados. Para tanto, foi realizada uma entrevista com os gestores a fim de conhecer as principais dificuldades enfrentadas na gestão das instituições. A aplicação do questionário e da entrevista foi realizada no mês de maio de 2011, contendo informaçóes relativas às receitas, aos custos e às despesas das instituiçóes do mês de abril do corrente ano.

Os dados da população atual e futura de idosos foram obtidos do relatório do IBGE de 2010, subsidiando a projeção do volume de recursos que será necessário para manter a população de idosos nas instituiçóes pesquisadas nos próximos anos.

Foi necessário utilizar as seguintes fórmulas para o cálculo do número de idosos, dos recursos financeiros e dos gastos necessários às instituiçóes estudadas nos próximos anos:

a) Gasto Médio (GM), que é o resultado da divisão do Gasto Total Anual (GTA), projetado a partir de informaçóes mensais, pela Quantidade de Idosos Atendidos (QIA).

$$
G M=\frac{G T A}{Q I A}
$$

b) Gasto Total no Ano t (GT t), que é o resultado da multiplicação da Quantidade de Idosos Atendidos no Ano t (QIA t) pelo Gasto Médio (GM).

$$
G T t=Q I A t * G M
$$

c) Proporção de Idosos Atendidos nas ILPIs (PII), que é o resultado da divisão da Quantidade de Idosos Atendidos (QIA) pela População Total de Idosos (PTI).

$$
P I I=\frac{Q I A}{P T I}
$$

d) Quantidade de Idosos Atendidos no Ano t (QIA t), que é o resultado da multiplicação da Proporção de Idosos Atendidos nas ILPIs (PII) pela População Total de Idosos no Ano t (PTI t).

$$
Q I A t=P I I * P T I t
$$

Foram estabelecidos os seguintes passos: (i) elencar quais são as principais fontes de recurso nas ILPIs filantrópicas e não filantrópicas; (ii) calcular quanto as ILPIs filantrópicas e não filantrópicas gastam por mês e quais são as principais despesas; (iii) identificar quais são os tipos de serviços prestados aos idosos; (iv) realizar uma projeção dos gastos para os próximos 20 anos. Após coletados os dados e projetados os gastos, receitas e despesas, foram realizadas as análises das informaçōes das entidades. $\mathrm{O}$ estudo não foi submetido a um comitê de ética em pesquisa, visto que trata somente de um levantamento de informaçóes a respeito da sustentabilidade econômica das ILPIs. Na próxima seção, apresentaremos os resultados da investigação.

\section{Resultados}

No resultado da pesquisa, ficou evidente que a maioria das instituições possui caráter filantrópico. Das seis 
instituiçôes analisadas, quatro são filantrópicas e apenas duas possuem finalidade lucrativa.

Grande parte do controle do ingresso de idosos nas institiçóes filantrópicas é feita pelo Centro de Referência Especializado de Assistência Social (CREAS). Quando é informado pela instituição credenciada o surgimento de vagas, é feita uma seleção dos idosos de acordo com o perfil, levando-se em conta aspectos financeiros, de saúde e da região em que a família reside.

Atualmente, 61\% dos idosos abrigados nas ILPIs são mulheres e 39\% são homens, de um total de 242 idosos contemplados pela análise. Um estudo com idosos de instituiçóes asilares do município de Natal/RN demonstra perfil semelhante ao do Distrito Federal, onde mais de $58 \%$ dos pesquisados eram do sexo feminino (DAVIM et al, 2004).

Com relação aos serviços oferecidos pelas ILPIs, constatou-se que todas as instituições oferecem atendimento médico, enfermagem e atividade lúdica. Dos outros serviços prestados, a atividade cultural está presente em cinco instituiçóes, a de terapia ocupacional em quatro, a de fisioterapia e de alongamento em três e a de psicologia em apenas duas.

Para cada idoso, existe uma média de 2,29 atendentes, dos quais, 0,82 está empregado e 1,47 trabalha como voluntário, fazendo algum tipo de atividade ou prestando ajuda sem qualquer tipo de retorno financeiro.

Quando se trata da força de trabalho, enquanto não há voluntários prestando serviços nas instituições privadas, $70 \%$ das equipes de instituiçóes filantrópicas são compostas por voluntários. Isso demonstra a importância que a comunidade dá à prestação de serviços à população de idosos do $\mathrm{DF}$, principalmente na realização de atividades lúdicas, de terapia ocupacional e de fisioterapia. No entanto, as instituiçóes, às vezes, ficam dependentes de açóes isoladas de um pequeno grupo de pessoas, pois não há uma garantia de que tais serviços serão contínuos. Vale frisar que nas instituiçóes filantrópicas existe menos de um empregado $(0,77)$ por idoso, e que nas não filantrópicas esse número é de mais de um $(1,02)$. Por outro lado, existem quase dois $(1,80)$ voluntários para cada idoso nas instituiçóes filantrópicas. Há necessidade urgente de preparação de mão de obra qualificada para saber lidar com os problemas biológicos do envelhecimento.

Os profissionais responsáveis por cuidar de idosos devem ter conhecimentos para lidar com patologias ou limitações que necessitem de atenção especial. Doenças, dificuldade de fala, idosos acamados, terapia medicamentosa, dietas e exercícios físicos são exemplos de cuidados e conhecimentos em que os profissionais devem se especilializar. Essas dificuldades podem ser reduzidas a partir da realização de capacitaçóes destinadas aos cuidadores para que eles possam prestar um atendimento mais efetivo e integral aos idosos. Dessa forma, o profissional vai desempenhar suas funções com mais entusiasmo e segurança, dispondo de informaçôes básicas para o seu trabalho (COLOMÉ et al, 2011).

Nas ILPIs privadas, a mensalidade que contempla a oferta de serviços para se hospedar um idoso pode chegar a um valor que oscila entre $\mathrm{R} \$ 2.000,00$ e R \$ 3.500,00, dependendo do grau de saúde, do tipo de quarto e dos cuidados especiais requeridos. Em outras instituiçóes do DF, o valor da mensalidade pode chegar a $\mathrm{R} \$ 8.000,00$.

Já nas instituiçôes filantrópicas, o governo estabelece a forma de participação, que não poderá exceder $70 \%$ de qualquer benefício previdenciário ou de assistência social recebido pelo idoso. É bom frisar que a Constituição Federal e a Lei no 8.742 , de 7 de dezembro de 1993 (Lei Orgânica da Assistência Social), asseguram ao cidadão brasileiro um benefício de prestação contínua no valor de um salário mínimo, pago por mês às pessoas com mais de 65 anos que não podem garantir sua sobrevivência por conta própria ou com o apoio da família. Logo, se o idoso receber um salário mínimo de $\mathrm{R} \$ 545,00$, deverá repassar para as entidades até $\mathrm{R} \$ 381,50$.

Quanto a fontes de recursos, a maior parcela de contribuição para a manutenção das seis ILPIs provém de mensalidades pagas pelos idosos ou por suas famílias, atingindo $46 \%$ da arrecadação total, em decorrência da mensalidade cobrada pelas instituiçóes particulares. Em seguida, 23\% das receitas são provenientes da contribuição beneficiária paga pelos idosos mantidos nas instituiçóes filantrópicas (ver tabela 1). 
Tabela 1. Fontes de recursos das entidades filantrópicas e não filantrópicas, Brasília (2011)

\begin{tabular}{lcccccc}
\hline $\begin{array}{l}\text { Fonte de Recursos } \\
\text { Mensal }\end{array}$ & \multicolumn{2}{c}{ Filantrópicas } & \multicolumn{2}{c}{ Não Filantrópicas } & \multicolumn{2}{c}{ Total } \\
\hline & $\mathrm{R} \$$ & $\%$ & $\mathrm{R} \$$ & $\%$ & $\mathrm{R} \$$ \\
\hline Mensalidade & - & $0,00 \%$ & $109.000,00$ & $100,00 \%$ & $109.000,00$ & $46,25 \%$ \\
\hline $\begin{array}{l}\text { Contribuição } \\
\text { Beneficiária }\end{array}$ & $54.583,50$ & $43,08 \%$ & - & $0,00 \%$ & $54.583,50$ & $23,16 \%$ \\
\hline Convênio com o GDF & $28.616,10$ & $22,59 \%$ & - & $0,00 \%$ & $28.616,10$ & $12,14 \%$ \\
\hline Doações & $27.100,00$ & $21,39 \%$ & - & $0,00 \%$ & $27.100,00$ & $11,50 \%$ \\
\hline Bazares & $9.000,00$ & $7,10 \%$ & - & $0,00 \%$ & $9.000,00$ & $3,82 \%$ \\
\hline Outros & $7.400,00$ & $5,84 \%$ & - & $0,00 \%$ & $7.400,00$ & $3,14 \%$ \\
\hline Total & $126.699,60$ & $100,00 \%$ & $109.000,00$ & $100,00 \%$ & $235.699,60$ & $100,00 \%$ \\
\hline
\end{tabular}

Fonte: Elaboração Própria

Além dessas receitas, advindas das mensalidades ou dos recursos previdenciários, o governo participa com $12 \%$ através de convênios, repassando um valor diário à instituição de $\mathrm{R} \$ 6,71$ para cada idoso independente e de $\mathrm{R} \$ 7,81$ para cada idoso dependente. Somente as ILPIs cadastradas nos CREAS poderão obter os recursos do Governo do Distrito Federal (GDF). Doações em dinheiro pela comunidade para as instituições filantrópicas representam $11 \%$, e outras fontes de recursos $7 \%$.

As filantrópicas dependem $43 \%$ da contribuição beneficiária dos idosos, $22 \%$ de recursos do Governo do Distrito Federal, via convênios, 22\% de doaçôes em dinheiro e $13 \%$ de outras fontes de renda.

Comparando com pesquisa realizada em âmbito nacional, referente à composição percentual do financiamento das instituições de longa permanência por natureza, de 2007 a 2009 (IPEA, 2011), as fontes de financiamento no país são praticamente as mesmas, seguindo em uma mesma proporção. Observa-se que as instituiçóes privadas são mantidas pelos residentes, chegando a quase $100 \%$ das receitas, enquanto as filantrópicas dependem da contribuição beneficiária, do financiamento público e de outras fontes, que representam mais de $55 \%$ do total arrecadado.

Vale destacar que, enquanto $45,4 \%$ das instituições no Brasil oferecem atividades que geram renda (IPEA, 2011), nas instituições estudadas do Distrito Federal não há nenhuma fonte própria de recursos provenientes de serviços ou mercadorias gerados por elas, demonstrando total dependência de recursos governamentais, dos asilados ou da comunidade.

Em se tratando de gastos (ver tabela 2), a parcela mais significativa, $56 \%$, refere-se ao pagamento de pessoal, incluindo médicos, enfermeiros e funcionários dedicados à manutenção da instituição. Os gastos com manutenção, incluindo aluguel, água, luz, telefone e materiais de limpeza representam quase $18 \%$ do total. Embora boa parte dos alimentos ofertados aos idosos seja proveniente de doaçôes (cujo montante não está incluído no compute do trabalho), 15\% dos gastos são destinados à compra de gêneros alimentícios. As fraldas geriátricas representam $9 \%$ das despesas (além das doaçôes não computadas), enquanto $2 \%$ referem-se a medicamentos. As instituiçôes normalmente não são responsáveis pela aquisição de remédios, ficando esse gasto a cargo do idoso e de seus familiares. 
Tabela 2. Despesas das entidades filantrópicas e não filantrópicas

\begin{tabular}{|c|c|c|c|c|c|c|}
\hline \multirow{2}{*}{ DESPESAS MENSAIS } & \multicolumn{2}{|c|}{ Filantrópicas } & \multicolumn{2}{|c|}{ Não Filantrópicas } & \multicolumn{2}{|c|}{ Total } \\
\hline & $\mathrm{R} \$$ & $\%$ & $\mathrm{R} \$$ & $\%$ & $\mathrm{R} \$$ & $\%$ \\
\hline \multirow[t]{2}{*}{ Pessoal } & & & & & & \\
\hline & $150.100,00$ & $59,78 \%$ & $45.000,00$ & $46,15 \%$ & $195.100,00$ & $55,97 \%$ \\
\hline Medicamentos & $6.000,00$ & $2,39 \%$ & - & $0,00 \%$ & $6.000,00$ & $1,72 \%$ \\
\hline Fraldas & $26.500,00$ & $10,55 \%$ & $5.500,00$ & $5,64 \%$ & $32.000,00$ & $9,18 \%$ \\
\hline Alimentação & $40.000,00$ & $15,93 \%$ & $13.500,00$ & $13,85 \%$ & $53.500,00$ & $15,35 \%$ \\
\hline Manutenção & $28.500,00$ & $11,35 \%$ & $33.500,00$ & $34,36 \%$ & $62.000,00$ & $17,79 \%$ \\
\hline Total & $251.100,00$ & $100,00 \%$ & $97.500,00$ & $100,00 \%$ & $348.600,00$ & $100,00 \%$ \\
\hline
\end{tabular}

Fonte: Elaboração Própria

Comparando-se os tipos de instituiçóes, a maior inconsistência está nas despesas com manutenção, pois, nas instituiçôes não filantrópicas, despesas com manutenção representam 34\% das despesas gerais, enquanto nas filantrópicas representam apenas 11\%. Outra grande diferença está no pagamento de pessoal, pois destinam-se 60\% nas instituições não filantrópicas e 46\% nas filantrópicas. Tanto no âmbito nacional como no Distrito Federal, o pagamento de pessoal tem a maior relevância. Conforme pesquisa do IPEA/SEDH/MDS e do CNPq, de 2011, 62,6\% dos gastos das instituiçóes de longa permanência são destinados ao pagamento de recursos humanos, $14,1 \%$ à alimentação, 5,3\% a medicamentos e $18,8 \%$ a outros tipos de serviços ou produtos.

Quanto à projeção dos gastos, segundo o censo realizado pelo IBGE em 2010, dos 2.570.160 habitantes do Distrito Federal, 197.613 (7,69\% do total) eram idosos, e na pesquisa ora realizada, apurou-se que apenas $0,2783 \%$ deles eram atendidos por ILPIs, chegando a um total de 550 idosos.
A projeção elaborada no âmbito do IBGE e do CODEPLAN/DF, Indicadores Sociodemográficos Prospectivos para o Distrito Federal 1991 - 2030, revela que a participação dos idosos na população total passará de 7,69\% em 2010 para 8,9\% em 2015, 10,40\% em 2020, 8,30\% em 2025 e 14,80\% em 2030.

Portanto, de acordo com a projeção, os idosos atendidos por ILPIs no DF passarão de $550 \mathrm{em} 2010$ para, aproximadamente, 708 em 2015, 875 em 2020, 731 em 2025 e 1.347 em 2030, caso haja alguma mudança na estrutura existente, pois atualmente as ILPIs estão com a capacidade de atendimento esgotada.

Considerando-se as despesas anuais por idoso atendido, calculadas a partir de dados mensais fornecidos pelas instituiçóes, verifica-se que será necessária uma receita de 24 milhóes de reais para atender os 1.347 idosos em 2030. Na tabela 3, é possível visualizar a projeção de despesas até o ano de 2030, subdividas nas fonte de recursos: convênio do governo, participação beneficiária do idoso, doaçóes em dinheiro, participação da comunidade e outros. 
Tabela 3. Projeção da quantidade de idosos atendidos e recursos necessários para as ILPIs até 2030

\begin{tabular}{|c|c|c|c|c|c|}
\hline & 2010 & 2015 & 2020 & 2025 & 2030 \\
\hline \multicolumn{6}{|l|}{ Total de idosos no DF } \\
\hline & 197.613 & 254.288 & 314.482 & 262.662 & 484.043 \\
\hline$\%$ de idosos no DF & $7,69 \%$ & $8,90 \%$ & $10,40 \%$ & $8,30 \%$ & $14,80 \%$ \\
\hline Quantidade de idosos & 550 & 708 & 875 & 731 & 1.347 \\
\hline Gasto anual em $\mathrm{R} \$$ & $9.950 .681,82$ & $12.804 .491,97$ & $15.835 .525,91$ & $13.226 .207,81$ & $24.373 .713,15$ \\
\hline $\begin{array}{l}\text { Repasse de convênio do } \\
\text { governo em } R \$\end{array}$ & 1.080.199,94 & $1.389 .996,36$ & $1.719 .031,36$ & $1.435 .775,87$ & $2.645 .897,43$ \\
\hline $\begin{array}{l}\text { Participação beneficiária } \\
\text { do idoso em R\$ }\end{array}$ & $2.060 .416,81$ & $2.651 .334,95$ & $3.278 .949,56$ & $2.738 .656,65$ & $5.046 .891,18$ \\
\hline Doações em R\$ & $1.022 .970,23$ & $1.316 .353,43$ & $1.627 .955,94$ & $1.359 .707,51$ & $2.505 .716,03$ \\
\hline $\begin{array}{l}\text { Doações da comunidade } \\
\text { em R\$̦ }\end{array}$ & $3.522 .510,91$ & $4.532 .750,97$ & $5.605 .727,71$ & 4.682.037,09 & $8.628 .219,86$ \\
\hline
\end{tabular}

Fonte: Elaboração Própria

O comportamento das despesas, bem como o repasse do governo, a parcela pagas dos idosos, as doaçóes em dinheiro e a participação da comunidade podem ser observados na tabela 3, cabendo destacar que a tendência de crescimento presente em todo período é invertida de 2020 para 2025, tendo em vista a queda de 10,40\% para $8,30 \%$ na projeção do percentual de idosos no DF em relação à população total (IBGE, 2011).

Os gastos anuais por idoso nas ILPIs tenderão a crescer bem mais que os recursos repassados pelo governo, pela comunidade e os oriundos das mensalidades pagas pelos idosos, demonstrando que a participação dos voluntários e as doações da sociedade continuarão tendo um papel importante para a manutenção dessas entidades. Mas, para que as ILPIs possam atender à demanda crescente de idosos, serão necessários novos investimentos. Pesquisas na área da gerontologia, que trata especificamente da otimização das relaçôes entre idosos e seus contextos sócio-espaciais, alertam para os cuidados que devem ser dados às condiçóes de moradia para idosos em termos de composição da habitação e de padróes de moradia; à natureza e ao impacto de

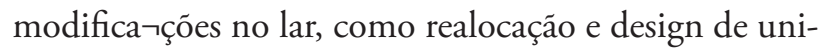
dades para idosos com demência ou outros cenários especializados, bem como cuidados ao lugar do envelhecimento em uma ampla perspectiva social e política (TOMASINI, 2005).

\section{Considerações finais}

Com os resultados apresentados, o governo e a sociedade passam a ter informaçóes mais detalhadas dos gastos ocorridos, bem como sobre a relevância do papel social das ILPIs, podendo, ainda, adotar estratégias e políticas públicas para a manutenção e a melhoria da qualidade de vida das pessoas envolvidas.

Os dados coletados por instituição, bem como sua consolidação, revelam que os recursos dos idosos (até $70 \%$ de aposentadoria) somados aos governamentais 
são insuficientes para a manutenção das ILPIs de caráter filantrópico, ficando clara uma dependência da sociedade, quer de doação em dinheiro, fraldas geriátricas ou alimentos, quer de trabalho voluntário.

Considerada a projeçấo do número de idosos e a projeção dos gastos até 2030, não há como manter as entidades sem a ajuda da sociedade, pois o governo contribui com menos de um quarto do montante de recursos dessas instituições, o que é insuficiente para custear os medicamentos e a alimentaçáo dos idosos atendidos.

Diante dessa dependência, os gestores buscam da sociedade ajuda e recursos financeiros para a manutenção das instituiçóes, o que demonstra ser um grande problema de sustentabilidade econômica, uma vez que o número de idosos irá aumentar, o número de componentes das famílias diminuir, e o número de cuidadores mulheres tenderá também a reduzir.

Isso poderá ser modificado se houver um novo direcionamento das políticas públicas voltadas para essa população, pois as ações de estímulo a doações em forma de dinheiro atualmente são insuficientes em relação às fontes de recursos obtidas pelas ILPIs. Em alguns casos, exigências da Agência Nacional de Vigilância Sanitária quanto às condições de oferta de serviços dificultam a existência de novas entidades. Há casas e abrigos não contemplados na pesquisa funcionando de forma irregular, sem condiçóes necessárias para a obtenção de recursos do governo.
Políticas educacionais quanto à formação de mão de obra qualificada devem ser aventadas, pois há pessoas idosas no Brasil sujeitas à violência dos mais variados tipos, que vão desde insultos até cárcere privado (CONSELHO DOS DIREITOS DO IDOSO DO DISTRITO FEDERAL, 2009), fato esse causado pela falta de pessoas preparadas para lidar com os problemas causados na velhice. Gastos com capacitação de atendentes, cuidadores, médicos e enfermeiros deverão ser intensificados, acarretando mudanças nas planilhas de custos das entidades. Haverá necessidade, também, de políticas de capacitação de novos especialistas que possam ofertar serviços de qualidade para uma faixa de habitantes carente de cuidados psicológicos e sociais.

Além do repasse de recursos governamentais, poderá o governo conceder incentivos fiscais às pessoas físicas e jurídicas, possibilitando maior aporte nas receitas das instituiçóes filantrópicas, uma vez que já existem incentivos dessa natureza voltados para crianças e adolescentes, como a cultura, a atividade audiovisual e o desporto. Com relação às ILPIs particulares, as mensalidades pagas pelos idosos se mostraram suficientes para a manutenção dos serviços ofertados, embora os gastos com medicamentos e com planos de saúde fiquem a cargo dos beneficiados.

\section{Referências}

ANVISA. Resolução da Diretoria Colegiada, 283, de 26 de setembro de 2005. Disponível em: <www.portalsaude.gov.br>. Acesso em 8 jun. 2011.

BOJORQUEZ-CHAPELA, I. et al. Depressive symptoms among poor older adults in Mexico: prevalence and associated factors. Revista Panamericana de Salud Pública/Pan American Journal of Public Health, Washington, DC, v. 26, n. 1, p. 70-77, 2009.

CADER, S. A. et al. Perfil da qualidade de vida e da autonomia funcional de idosos asilados em uma instituição filantrópica no município do Rio de Janeiro. Fitness \& Performance Journal, Rio de Janeiro, v. 5, n. 4, p. 256-261, jul./aug. 2006.

CARAMAGO, A. A. Características das instituições de longa permanência para idosos: região Centro-Oeste. Brasília: IPEA, 2008. 160p.
CARAMAGO, A. A.; PASINATO, M. T. O Envelhecimento Populacional na Agenda das Políticas Públicas. In: CAMARANO, A. A. (Org.). Os novos idosos brasileiros: muito além dos 60. Rio de Janeiro: IPEA, 2004. p. 253-292. v. 1

CHAIMOWICZ, F.; GRECO, D. B. Dinâmica da institucionalização de idosos em Belo Horizonte. Revista de Saúde Pública, São Paulo, v. 33, n. 5, p. 454-460, out. 1999.

COLOMÉ, I.C.S. et al. Cuidar de idosos institucionalizados: características e dificuldades dos cuidadores. Revista Eletrônica de Enfermagem, Goiânia, v. 13, n. 2, p.306-312, abr./jun. 2011.

COMPANHIA DE PLANEJAMENTO DO DISTRITO FEDERAL (CODEPLAN). Indicadores Sociodemográficos Prospectivos para o Distrito Federal 1991 - 2030. Brasília: CODEPLAN, 2009. 
Disponível em: <http://www.codeplan.df.gov.br/>. Acesso em 8 jun. 2011.

CONSELHO DOS DIREITOS DO IDOSO DO DISTRITO FEDERAL (CDI/DF). Idoso: informações sobre os direitos, políticas públicas e guia de serviços e benefícios sociais. Brasília: CDI/DF, 2009.

DAVIM, R. M. B. et al. Estudo com idosos de instituições asilares no município de Natal/RN: características socioeconômicas e de saúde. Revista Latino-Americana de Enfermagem, São Paulo, v. 12, n. 2, p. 518-524, maio/ jun. 2004.

FERREIRA, C. G.; ALEXANDRE, T. S.; LEMOS, N. D. Fatores associados à qualidade de vida de cuidadores de idosos em assistência domiciliária. Saúde e Sociedade, São Paulo, v. 20, n. 2, abr./jun. 2011.

HOCHMAN, G.; ARRETCHE, M.; MARQUES, E. Políticas públicas no Brasil. Rio de Janeiro: Ed. FIOCRUZ, 2008. 398p.

INSTITUTO BRASILEIRO DE GEOGRAFIA E ESTATÍSTICA (IBGE). Censo 2010. Rio de Janeiro: IBGE, 2011. Disponível em: <http:// www.ibge.gov.br>. Acesso em 8 jun. 2011.

LARANJEIRA, C. A.."Velhos são os Trapos": do positivismo clássico à nova era. Saúde e Sociedade, São Paulo, v. 19, n.4, p.763-770, 2010.

LOURES, R. C. R. Sustentabilidade XXI Educar e Inovar sob nova consciência. São Paulo: Gente, 2009.
MCKINSEY \& Company, Inc. Negócios sociais sustentáveis: estratégias inovadoras para o desenvolvimento social. São Paulo: Editora Peirópolis, 2006. 104p.

MELO, G.F. et al. Análise do nível de atividade física nas casas de repouso e instituições filantrópicas (asilos) do Distrito Federal. Revista Digital-Buenos Aires, Buenos Aires, a. 9, n. 62, 2003.

RAMOS, L. R. Fatores determinantes do envelhecimento saudável em idosos residentes em centro urbano: Projeto Epidoso, São Paulo. Caderno de Saúde Pública, Rio de Janeiro, v. 19, n. 3, p. 793798, maio/jun. 2003.

RODRIGUES, N.; RAUTH, J. Os Desafios do envelhecimento no Brasil. In: FREITAS, E. et al. Tratado de Geriatria e Gerontologia. Rio de Janeiro: Guanabara, 2002. p. 106-110.

SANDIFORD, P. J.; DIVERS, P. The public house and its role in society's margins. International Journal of Hospitality Management, Orlando, v. 30, n. 4, p. 765-773, dec. 2011.

TOMASINI, S. L. V. Envelhecimento e planejamento do ambiente construído: em busca de um enfoque interdisciplinar. Revista Brasileira de Ciências do Envelhecimento Humano - RBCEH, Passo Fundo, v.2, n.1, p. 76-88, jan.jjun. 2005.

YUNUS, M. Um mundo sem pobreza: a empresa social e o futuro do capitalismo. São Paulo: Editora Ática, 2008. 263p.

Recebido para publicação em Setembro/2011

Versão definitiva em Setembro/2012

Suporte financeiro: Não houve

Conflito de interesse: Inexistente 